\title{
Effect of Melatonin on Blood Pressure and Nitric Oxide Generation in Rats With Metabolic Syndrome
}

\author{
J. KLIMENTOVA ${ }^{1}$, M. CEBOVA ${ }^{1}$, A. BARTA ${ }^{1}$, Z. MATUSKOVA ${ }^{1}$, S. VRANKOVA ${ }^{1}$, \\ R. REHAKOVA ${ }^{1}$, M. KOVACSOVA ${ }^{1}$, O. PECHANOVA ${ }^{1}$ \\ ${ }^{1}$ Institute of Normal and Pathological Physiology and Centre of Excellence for Examination of \\ a Regulatory Role of Nitric Oxide in Civilization Diseases, Slovak Academy of Sciences, \\ Bratislava, Slovak Republic
}

Received June 21, 2016

Accepted September 5, 2016

\begin{abstract}
Summary
Melatonin, a multitasking indolamine, seems to be involved in a variety of physiological and metabolic processes via both receptor-mediated and receptor-independent mechanisms. The aim of our study was to find out whether melatonin can affect blood pressure (BP), nitric oxide synthase (NOS) activity, eNOS and nNOS protein expressions in rats with metabolic syndrome (SHR/cp). Rats were divided into four groups: 6-week-old male WKY andSHR/cp and age-matched WKY and SHR/cp treated with melatonin (10 mg/kg/day) for 3 weeks. BP was measured by tailcuff plethysmography. NOS activity, eNOS and nNOS protein expressions were determined in the heart, aorta, brain cortex and cerebellum. $\mathrm{MT}_{1}$ receptors were analyzed in the brain cortex and cerebellum. In SHR/cP rats, BP was decreased after melatonin treatment. In the same group, melatonin did not affect NOS activity and eNOS protein expression in the heart and aorta, while it increased both parameters in the brain cortex and cerebellum. Interestingly, melatonin elevated MT1 protein expression in the cerebellum. Neuronal NOS protein expression was not changed within the groups. In conclusion, increased NOS activity/eNOS upregulation in particular brain regions may contribute partially to BP decrease in SHR/cp rats after melatonin treatment. Participation of $\mathrm{MT}_{1}$ receptors in this melatonin action may be supposed.
\end{abstract}

\section{Key words}

Melatonin $\bullet \mathrm{MT}_{1}$ receptors $\bullet$ Metabolic syndrome $\bullet$ Nitric oxide • Heart • Aorta • Brain

\section{Corresponding author}

O. Pechanova, Institute of Normal and Pathological Physiology, Slovak Academy of Sciences, Sienkiewiczova 1, 81371 Bratislava, Slovak Republic. E-mail: olga.pechanova@savba.sk

\section{Introduction}

Melatonin, a multitasking indolamine ( $N$-acetyl5-methoxytryptamine), shows potent receptor-dependent and -independent actions, which may participate on regulation of both blood pressure and metabolic alterations (Pechanova et al. 2014). Receptor-dependent effects are mediated predominantly through $\mathrm{MT}_{1}$ and $\mathrm{MT}_{2}$ G-protein coupled receptors. The pleiotropic receptor-independent effects of melatonin with a possible impact on blood pressure and risk factors of metabolic syndrome involve reactive oxygen species scavenging and activation/overexpression of several antioxidant enzymes or protecting them from oxidative damage. Acting as a direct scavenger, melatonin is able to neutralize different free radicals, mainly superoxide anion and hydroxyl radical (Favero et al. 2014, Pechanova et al. 2015, Alonso-Alconada et al. 2013). Indirect antioxidant actions of melatonin reside in the stimulation of gene expressions and activation of superoxide dismutase, catalase, glutathione peroxidase (Tomas-Zapico and Coto-Montes 2005) and improvement of mitochondrial efficiency (Acuna-Castroviejo et al. 2001). Since attenuation of the free radical burden in the central nervous system (CNS) was shown to attenuate hypertension (Kojsova et al. 2006), the antioxidant nature 
of melatonin may act beneficially particularly in the brain - the tissue highly susceptible to the increased oxidative load (Pechanova et al. 2006). Melatonin has been shown to be protective in CNS on several different levels: it reduces free radical burden, improves endothelial dysfunction, reduces inflammation and shifts the balance between the sympathetic and parasympathetic system in favor of the parasympathetic one (Tan et al. 2007).

In the CNS, the relation of melatonin regarding its effect on nitric oxide synthase (NOS) activity and/or NOS isoforms expression, is rather complex. This indolamine and its derivates inhibit neuronal NOS (nNOS) and inducible NOS (iNOS), while the effect on endothelial NOS (eNOS) is less clear. Melatonin inhibits iNOS through nuclear factor kappa B (NF- $\mathrm{B}$ )-dependent signaling pathway (Mohan et al. 1995, Reiter et al. 2000, Mauriz et al. 2013), and eNOS via modification of $\mathrm{Ca}^{2+}$-calmodulin complex (Pozo et al. 1997). Neuronal NOS is activated by calcium similarly to eNOS and analogous mechanism in melatonin-nNOS interaction in the brain may be supposed.

Recently it was found that simultaneous application of melatonin with lisinopril or amlodipine had the normalizing effect on metabolic parameters in patients with arterial hypertension (Shatilo et al. 2012). Obese spontaneously hypertensive SHR/NDmcr-cp/cp $(\mathrm{SHR} / \mathrm{cp})$ rats, in which the leptin receptor gene has been knocked out, represent a useful model for monitoring parameters associated with metabolic syndrome, since this respective model develops hypertension, obesity, hyperlipidemia, hyperinsulinemia and hyperglycemia (Michaelis et al. 1984, Striffler et al. 1998, Nagase and Fujita 2010). Moreover, several studies also reported elevated circulating levels of oxidative stress markers and disturbance in the nitric oxide/cyclic guanosine monophosphate (cGMP) pathway in SHR/cp rats (Yamaguchi et al. 2006, Kagota et al. 2006).

Thus, the aim of our study was to find out whether melatonin can affect blood pressure in SHR/cp rats and induce related changes in NOS activity and eNOS and nNOS protein expressions. Participation of brain $\mathrm{MT}_{1}$ receptors in melatonin action was studied as well.

\section{Methods}

\section{Chemicals and drugs}

All of the chemicals used were purchased from Sigma Chemicals Co. (Germany), when not specified.

\section{Animals and treatment}

The experiments were carried out in male normotensive Wistar-Kyoto rats (WKY) and hypertensive rats with metabolic syndrome - SHR/ND mcr-cp (cp/cp) $(\mathrm{SHR} / \mathrm{cp})$ housed in a room with a maintained temperature $\left(22 \pm 2{ }^{\circ} \mathrm{C}\right)$, relative humidity $(55 \pm 10 \%)$, and 12-h light/dark cycle. The animals had free access to standard lab chow (pelleted ST-1 diet) and water ad libitum. The SHR/cp rats were obtained from Charles River US laboratories. All procedures and experimental protocols were approved by the Ethical Committee of the Institute of Normal and Pathological Physiology SAS, and conformed to the European Convention on Animal Protection and Guidelines on Research Animal Use.

Rats were divided into four groups: control 6-week-old male WKY and SHR/cp and age-matched WKY and SHR/cp rats orally treated with melatonin ( $10 \mathrm{mg} / \mathrm{kg} /$ day) for 3 weeks ( $\mathrm{n}=6$ in each group). Systolic blood pressure was measured by tail-cuff plethysmography every week. At the end of experiment the animals were sacrificed and body weight (BW), heart weight (HW), and tibia length (TL) were determined. Samples of the heart left ventricle (LV), aorta, brain cortex and cerebellum were used for the determination of NOS activity and Western blot analysis.

\section{Total NOS activity}

Total NOS activity was determined in crude homogenates of LV, aorta, brain cortex and cerebellum by measuring L- $\left[{ }^{3} \mathrm{H}\right]$ citrulline formation from L- $\left[{ }^{3} \mathrm{H}\right]$ arginine (MP Biochemicals, California, USA) as described elsewhere (Pechanova et al. 1997, Bredt and Snyder 1990). NOS activity was expressed as pkat $/ \mathrm{min}$ per gram of protein.

\section{Western blot analysis}

Samples of the tissues (LV, aorta, brain cortex and cerebellum) were probed with a polyclonal rabbit anti-endothelial NOS, anti-neuronal NOS antibodies and antibodies for MT1A-R (Santa Cruz, USA) as described elsewhere (Bourcier et al. 1997). Antibodies were detected using a secondary peroxidase-conjugated antirabbit antibody (Santa Cruz, USA). The bands were visualized using the enhanced chemiluminescence system (ECL, Amersham, UK) and analyzed densitometrically using Photo-Capt V.99 software.

\section{Statistical analysis}

Results are expressed as means \pm SEM. Oneway ANOVA and Duncan's test were used for statistical 
analysis. $\mathrm{P}<0.05$ value was considered statistically significant.

\section{Results}

Weight ratios and systolic blood pressure (SBP)

In $\mathrm{SHR} / \mathrm{cp}$ rats body weight, heart weight and relative heart weight (calculated as the ratio of HW to TL) were significantly higher in comparison to control WKY rats. Melatonin treatment did not affect these parameters in any rat strain (Table 1).

Table 1. Effects of melatonin treatment on body weight (BW), heart weight $(\mathrm{HW})$ and heart weight/tibia length $\mathrm{HW} / \mathrm{TL}$ ratio.

\begin{tabular}{llll}
\hline & $\begin{array}{l}\text { BW } \\
\mathbf{( g )}\end{array}$ & $\begin{array}{l}\text { HW } \\
\mathbf{( m g )}\end{array}$ & $\begin{array}{l}\text { HW/TL } \\
\mathbf{( m g / m m})\end{array}$ \\
\hline$W K Y$ & $249 \pm 5$ & $814 \pm 17$ & $22 \pm 0.4$ \\
$W K Y+M E L$ & $250 \pm 4$ & $819 \pm 21$ & $23 \pm 0.5$ \\
$S H R-c p$ & $315 \pm 16^{*}$ & $878 \pm 29^{*}$ & $26 \pm 0.6^{*}$ \\
SHR-cp $+M E L$ & $323 \pm 16^{*}$ & $867 \pm 20^{*}$ & $26 \pm 0.7$ \\
\hline
\end{tabular}

WKY - Wistar Kyoto rats, SHR-cp - rats with metabolic syndrome, MEL - melatonin treatment $(10 \mathrm{mg} / \mathrm{kg} / \mathrm{day})$. Data are means \pm SEM; significant differences ${ }^{*} \mathrm{P}<0.05$ compared with WKY rats.

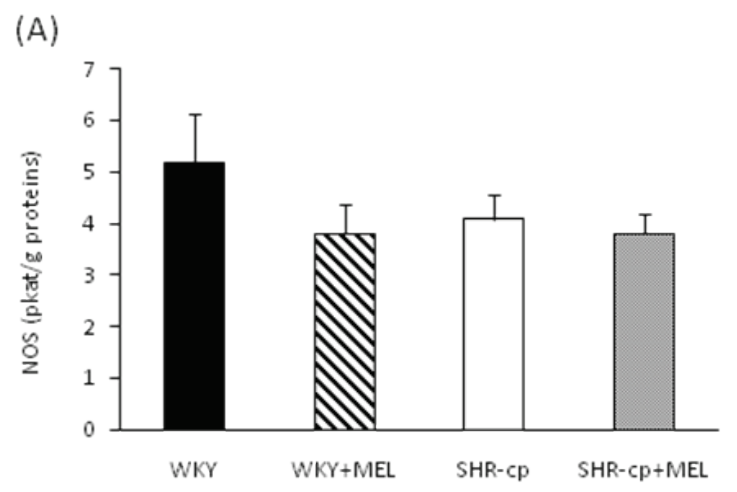

(C)

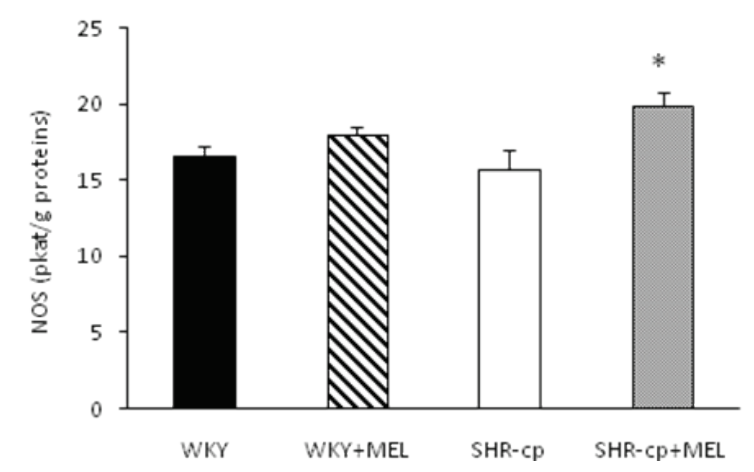

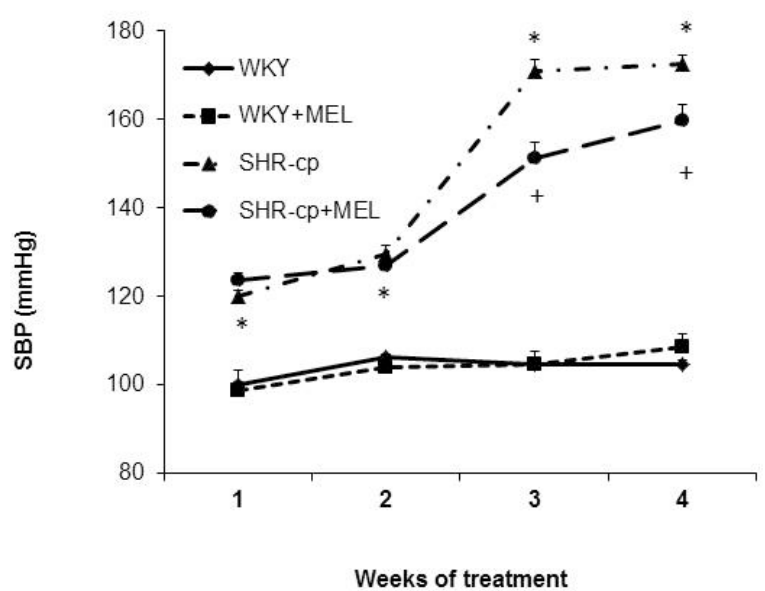

Fig. 1. Effect of melatonin (MEL) treatment on systolic blood pressure (SBP) in normotensive Wistar-Kyoto rats (WKY) and hypertensive rats with metabolic syndrome (SHR-cp). * $\mathrm{p}<0.05$ compared with WKY, $+p<0.05$ compared with SHR-cp.

Melatonin treatment did not affect SBP of normotensive WKY controls. SBP of SHR/cp rats was significantly higher during the whole experiment and melatonin treatment decreased it by $10 \%$ already after the second week of the treatment. This decrease persisted till the end of the treatment in comparison to age-matched untreated rats (159.6 vs.172.5 mm Hg, p<0.05) (Fig. 1).

(B)

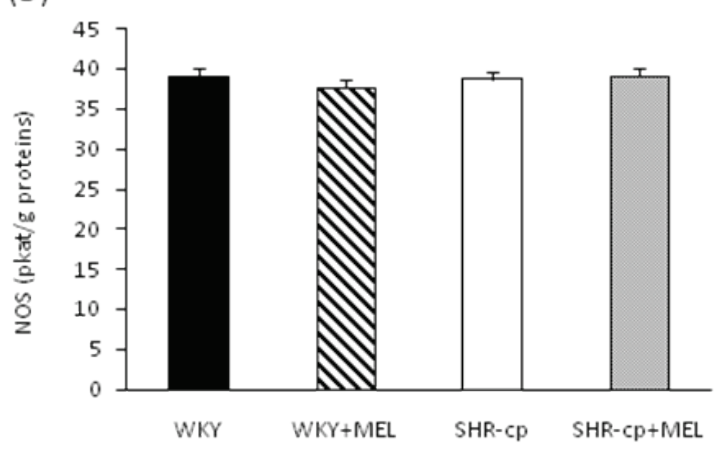

(D)

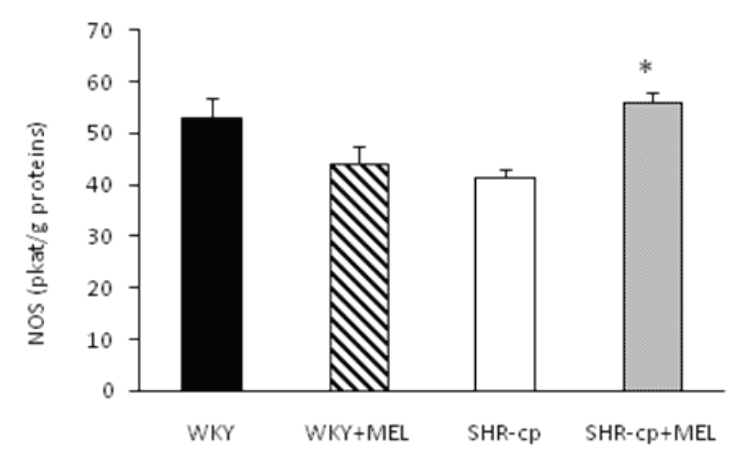

Fig. 2. Effect of melatonin (MEL) treatment on nitric oxide synthase (NOS) activity in the left ventricle (LV) (A), aorta (B), brain cortex (C) and cerebellum (D) of Wistar-Kyoto rats (WKY) and rats with metabolic syndrome (SHR-cP). * $p<0.05$ compared with respective control groups without MEL treatment. 


\section{Total NOS activity}

No significant changes in total NOS activity were found in the tissues of WKY and SHR/cp rats. After melatonin treatment, total NOS activity was not changed significantly in the LV and aorta within the groups (Figs $2 \mathrm{~A}$ and $2 \mathrm{~B}$ ). However, in $\mathrm{SHR} / \mathrm{cp}$ rats melatonin treatment increased total NOS activity in brain cortex by $25 \%(\mathrm{p}<0.05)$ (Fig. $2 \mathrm{C})$ and in cerebellum by $35 \%$ $(p<0.05)$ (Fig. 2D). There were no changes in total NOS activity after melatonin treatment in the WKY group.

\section{Western blot analysis}

Melatonin treatment increased eNOS protein expression in the brain cortex and cerebellum of both

(A)

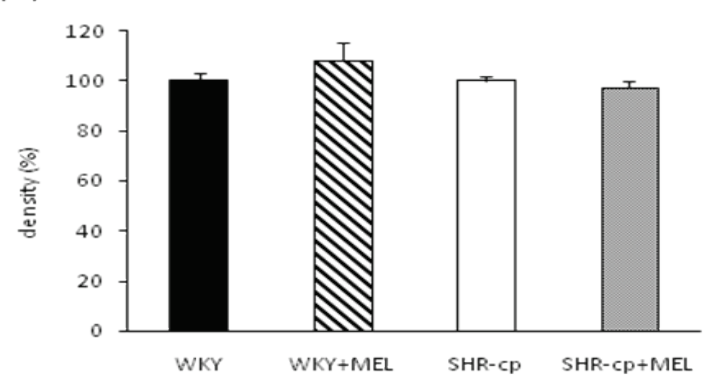

(C)

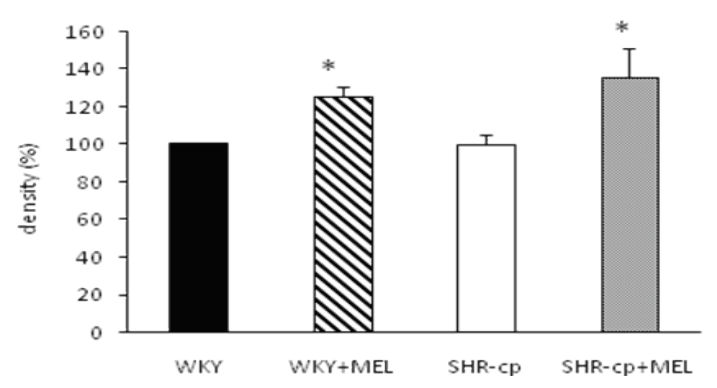

WKY (by $25 \%$ and $17 \%$, respectively) and SHR/cp rats (by $36 \%$ and $15 \%$, respectively) $(\mathrm{p}<0.05)$. On the other hand, eNOS protein expression in the LV and aorta remained unchanged (Figs 3A, 3B, 3C and 3D).

No changes in nNOS protein expression were found either in the LV and aorta or brain cortex and cerebellum within the groups (data not shown).

In WKY rats melatonin treatment increased protein expression of $\mathrm{MT}_{1}$ receptors in the brain cortex by $15 \%$ and cerebellum by $22 \%(\mathrm{p}<0.05)$. In SHR/cp rats melatonin treatment increased significantly protein expression of $\mathrm{MT}_{1}$ receptors in the cerebellum by $18 \%$ $(p<0.05)$. Nevertheless, there was a tendency to elevation in the brain cortex as well (Figs 4A and 4B).

(B)

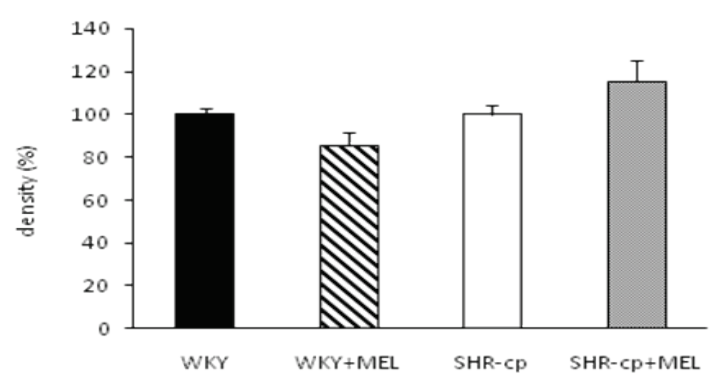

(D)

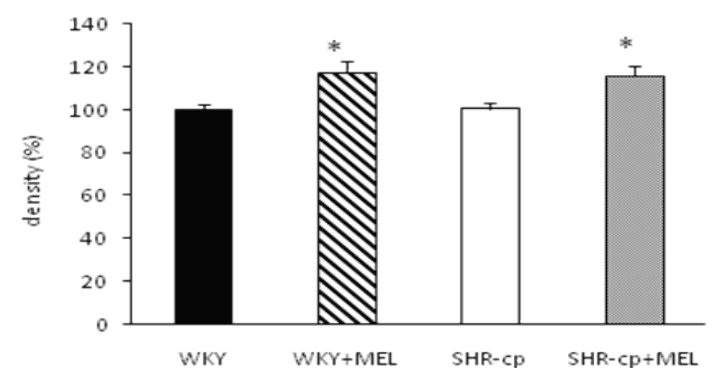

Fig. 3. Effect of melatonin (MEL) treatment on expression of endothelial nitric oxide synthase (eNOS) in the left ventricle (LV) (A), aorta (B), brain cortex (C) and cerebellum (D) of Wistar-Kyoto rats (WKY) and rats with metabolic syndrome (SHR-cp). ${ }^{*} \mathrm{p}<0.05$ compared with respective control groups without MEL treatment.

(A)

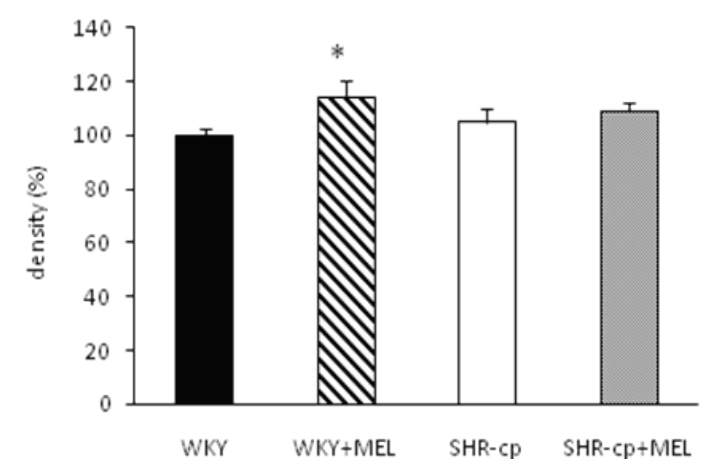

(B)

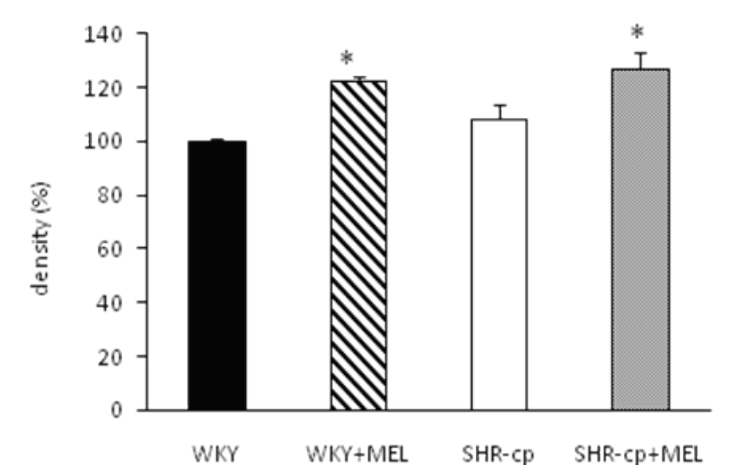

Fig. 4. Effect of melatonin (MEL) treatment on expression of melatonin receptors type $1\left(M_{1}\right)$ in the brain cortex (A) and cerebellum (B) of Wistar-Kyoto rats (WKY) and rats with metabolic syndrome (SHR-cp). $*$ p $<0.05$ compared with respective control groups without MEL treatment. 


\section{Discussion}

The SHR/NDmcr-cp rat has a genetic background from the spontaneously hypertensive rat (SHR) and carries nonsense mutation of leptin receptor derived from the obese Koletsky rat. SHR/NDmcr-cp rats develop severe hypertension compared with age-matched normotensive control WKY. Their systolic blood pressure reaches $200 \mathrm{~mm} \mathrm{Hg}$ at 12 weeks of age (Michaelis et al. 1984). Moreover, they are characterized by increased body and heart weights (Kagota et al. 2009, Janega et al. 2014), which was clearly confirmed by our study (Table 1). Furthermore, we have documented increased relative heart weight (normalized by tibia length) in this respective model. Fluctuations in body weight as occur with obesity make body weight an unreliable reference for normalizing heart weight. We therefore used tibia length, which remains constant with overweight, for calculating relative heart weight. Melatonin treatment did not affect either body weight or relative heart weight within the groups. However, in $\mathrm{SHR} / \mathrm{cp}$ rats melatonin decreased systolic blood pressure significantly already after the second week of the treatment and SBP reduction persisted till the end of the experiment. Similar blood pressure reduction we have seen in melatonin-treated SHR rats (Pechanova et al. 2007, Simko et al. 2009) and it was also reported in other experimental studies (Huang et al. 2013, Siew-Keah et al. 2014).

We have also analyzed the contribution of NOS activity in the blood pressure reduction after melatonin treatment. Interestingly, in $\mathrm{SHR} / \mathrm{cp}$ rats melatonin did not affect NOS activity and eNOS protein expression in the left ventricle and aorta, while it increased these parameters in the brain cortex and cerebellum. We admit that peripheral mechanisms of blood pressure regulation are much more thoroughly considered than those at the level of central nervous system, involving predominantly the relative dominance of sympathetic and reninangiotensin systems (Brunová et al. 2015). In SHR, the acute administration of melatonin reduced blood pressure along with norepinephrine levels (K-Laflamme et al. 1998). The acute administration of melatonin to normotensive rats also reduced blood pressure, heart rate along with the reduction of serotonin levels in corpus striatum and hypothalamus (Chuang et al. 1993). Moreover, in these experiments, the effect of melatonin on blood pressure and heart rate was abolished by spinal transection or bilateral vagotomy, suggesting the involvement of sympathetic inhibition or parasympathetic stimulation by melatonin (Chuang et al. 1993). Chronic administration of melatonin, similarly like $\mathrm{N}$-acetylcysteine, decreased blood pressure and heart rate and improved the chronotropic response to isoproterenol, in association with the inhibition of sympathetic activity (Girouard et al. 2003). In young healthy men, melatonin reduced pulsatile index and systolic blood pressure along with norepinephrine levels (Arangino et al. 1999) and reduced blood pressure and pulse wave velocity in association with the attenuation of sympathetic tone (Yildiz et al. 2006). These sympatholytic effects of melatonin may be involved in the blood pressure reducing effect of melatonin seen in SHR (Pechanova et al. 2007), L-NAME hypertensive rats (Paulis et al. 2010a, Paulis et al. 2010b), healthy volunteers (Arangino et al. 1999) or patients with essential hypertension (Simko and Pechanova 2009). The association of melatonin administration with sympatholytic effects may suggest a serious role of the central effects of melatonin on blood pressure regulation.

It is true that central NO can reduce blood pressure through the attenuation of sympathetic activity in hypertensive rats (Zhou et al. 2014, Ramachandra et al. 2014, Pechanova and Simko 2009). Thus, we hypothesized that melatonin may contribute to blood pressure reduction by increasing brain NOS activity with the attenuation of sympathetic tone also in our experimental study. The question arises which NOS isoform may contribute mostly to this blood pressure reduction. Although Guo et al. (2009) suggested a predominant role of nNOS in this process, other studies preferred increased eNOS expression in both sympathetic activity and blood pressure reduction (Kimura et al. 2007, Zhu et al. 2016, Kishi et al. 2001). In accordance with the latter studies, in our experiment with SHR/cp rats, melatonin treatment increased brain eNOS, while it had no effect on nNOS protein expression. Thus, we assume that in the $\mathrm{SHR} / \mathrm{cp}$ rats melatonin may upregulate rather brain eNOS with a decreasing effect on blood pressure.

Moreover, it has been shown that in stressinduced hypertensive rats, melatonin levels in the anterior hypothalamic area were reduced. A microinjection of melatonin into this site reduced blood pressure along with increased GABAergic activity and reduced glutamatergic activity in the rostral ventrolateral medulla. This effect was prevented by $\mathrm{MT}_{1} / \mathrm{MT}_{2}$ blockade (Xia et al. 2008). Since in SHR/cp rats NOS activity was increased in the brain parts like brain cortex and cerebellum, we 
analyzed protein expression of $\mathrm{MT}_{1}$ receptors in these brain regions. Interestingly, in our study melatonin not only increased brain NOS activity and decreased blood pressure but also elevated $\mathrm{MT}_{1}$ protein expression. It was hypothesized that the activation of melatonin receptors on endothelial cells would trigger NO production and contribute to blood pressure reduction (Paulis and Simko 2007). It seems, however, that melatonin receptors may regulate blood pressure also through the central mechanisms, since the highest density of melatonin receptors has been shown in the central nervous system (Malpaux et al. 2001, Vaněček and Janský 1989, Duncan et al. 1989).

Taken together, increased NOS activity and eNOS upregulation in the brain may contribute to blood pressure decrease in $\mathrm{SHR} / \mathrm{cp}$ rats after melatonin treatment. Participation of $\mathrm{MT}_{1}$ receptors in melatonin action may be supposed.

\section{Conclusions}

For the first time it has been shown, that melatonin may reduce blood pressure in rats with metabolic syndrome by increased production of central nitric oxide. Involvement of eNOS and $\mathrm{MT}_{1}$ protein expressions in the brain is supposed. However, mechanisms of $\mathrm{MT}_{1}$-melatonin-NO interplay at the CNS level leading to blood pressure reduction need to be more clarified. The inhibition of sympathetic nerve activity by nitric oxide is suggested.

\section{Conflict of Interest}

There is no conflict of interest.

\section{Acknowledgements}

This study was elaborated within the projects APVV0742-10, APVV-14-0932, VEGA 2/0195/15, 2/0144/14 and $2 / 0165 / 15$.

\section{References}

ACUNA-CASTROVIEJO D, MARTIN M, MACIAS M, ESCAMES G, LEON J, KHALDY H, REITER RJ: Melatonin, mitochondria, and cellular bioenergetics. J Pineal Res 30: 65-74, 2001.

ALONSO-ALCONADA, D, ALVAREZ A, ARTEAGA O, MARTÍNEZ-IBARGÜEN A, HILARIO E: Neuroprotective effect of melatonin: a novel therapy against perinatal hypoxia-ischemia. Int J Mol Sci 14: 9379-9395, 2013.

ARANGINO S, CAGNACCI A, ANGIOLUCCI M, VACCA AM, LONGU G, VOLPE A, MELLIS GB: Effects of melatonin on vascular reactivity, catecholamine levels, and blood pressure in healthy men. Am J Cardiol 83: 1417-1419, 1999.

BOURCIER T, SUKHOVA G, LIBBY P: The nuclear factor kappa-B signaling pathway participates in dysregulation of vascular smooth muscle cells in vitro and in human atherosclerosis. J Biol Chem 272: 15817-15824, 1997.

BREDT DS, SNYDER SH: Isolation of nitric oxide synthetase, a calmodulin-requiring enzyme. Proc Natl Acad Sci USA 87: 682-685, 1990.

BRUNOVÁ A, BENCZE M, BEHULIAK M, ZICHA J: Acute and chronic role of nitric oxide, renin-angiotensin system and sympathetic nervous system in the modulation of calcium sensitization in Wistar rats. Physiol Res 64: 447-457, 2015.

CHUANG JI, CHEN SS, LIN MT: Melatonin decreases brain serotonin release, arterial pressure and heart rate in rats. Pharmacology 47: 91-97, 1993.

DUNCAN MJ, TAKAHASHI JS, DUBOVICH ML: Characteristics and autoradiographic localization of 2-[ $\left[{ }^{125} \mathrm{I}\right]$ iodomelatonin binding sites in Djungarian hamster brain. Endocrinology 125: 1011-1018, 1989.

FAVERO G, RODELLA LF, REITER RJ, REZZANI R: Melatonin and its atheroprotective effects: A review. Mol Cell Endocrinol 382: 926-937, 2014.

GIROUARD H, CHULAK CH, LEJOSSEC M, LAMONTAGNE D, DE CHAMPLAIN J: Chronic antioxidant treatment improves sympathetic functions and $\beta$-adrenergic pathway in the spontaneously hypertensive rats. J Hypertens 21: 179-188, 2003.

GUO ZL, TJEN-A-LOOI SC, FU LW, LONGHURST JC: Nitric oxide in rostral ventrolateral medulla regulates cardiac-sympathetic reflexes: role of synthase isoforms. Am J Physiol Heart Circ Physiol 297: H1478-H1486, 2009. 
HUANG L, ZHANG C, HOU Y, LAUDON M, SHE M, YANG S, DING L, WANG H, WANG Z, HE P, YIN W: Blood pressure reducing effects of piromelatine and melatonin in spontaneously hypertensive rats. Eur Rev Med Pharmacol Sci 17: 2449-2456, 2013.

JANEGA P, KLIMENTOVA J, BARTA A, KOVACSOVA M, VRANKOVA S, CEBOVA M, CIERNA, Z, MATUSKOVA Z, JAKOVLJEVIC V, PECHANOVA O: Red wine extract decreases pro-inflammatory markers, nuclear factor- $\mathrm{B}$ and inducible NOS, in experimental metabolic syndrome. Food Funct 5: 22022207, 2014.

KAGOTA S, YAMAGUCHI Y, TANAKA N, KUBTA Y, KOBAYASHI K, NEJIME N, NAKAMURA K, KUNITOMO M, SHINOZUKA K: Disturbances in nitric oxide/cyclic guanosine monophosphate system in SHR/NDmcr-cp rats, a model of metabolic syndrome. Life Sci 78: 1187-1196, 2006.

KAGOTA S, TADA Y, NEJIME N, NAKAMURA K, KUNITOMO M, SHINOZUKA K: Chronic production of peroxynitrite in the vascular wall impairs vasorelaxation function in SHR/NDmcr-cp rats, an animal model of metabolic syndrome. J Pharmacol Sci 109: 556-564, 2009.

KIMURA Y, HIROOKA Y, SAGARA Y, SUNAGAWA K: Long-acting calcium channel blocker, azelnidipine, increases endothelial nitric oxide synthase in the brain and inhibits sympathetic nerve activity. Clin Exp Hypertens 29: 13-21, 2007.

KISHI T, HIROOKA Y, SAKAI K, SHIGEMATSU H, SHIMOKAWA H, TAKESHITA A: Overexpression of eNOS in the RVLM causes hypotension and bradycardia via GABA release. Hypertension 38: 896-901, 2001.

K-LAFLAMME A, WU L, FOUCART S, DE CHAMPLAIN J: Impaired basal sympathetic tone and a1-adrenergic responsiveness in association with the hypotensive effect of melatonin in spontaneously hypertensive rats. $\mathrm{Am}$ J Hypertens 11: 219-229, 1998.

KOJSOVA S, JENDEKOVA L, ZICHA J, KUNES J, ANDRIANTSITOHAINA R, PECHANOVA O: The effect of different antioxidants on nitric oxide production in hypertensive rats. Physiol Res 55 (Suppl 1): S3-S16, 2006.

MALPAUX B, MIGAUD M, TRICOIRE H, CHEMINEAU P: Biology of mammalian photoperiodism and the critical role of the pineal gland and melatonin. J Biol Rhythms 16: 336-347, 2001.

MAURIZ JL, COLLADO PS, VENEROSO C, REITER RJ, GONZÁLEZ-GALLEGO J: A review of the molecular aspects of melatonin's anti-inflammatory actions: recent insights and new perspectives. J Pineal Res 54: 1-14, 2013.

MICHAELIS OE, ELLWOOD KC, JUDGE JM, SCHOENE NW, HANSEN CT: Effect of dietary sucrose on the SHR/N-corpulent rat: a new model for insulin-independent diabetes. Am J Clin Nutr 39: 612-618, 1984.

MOHAN N, SADEGHI K, REITER RJ, MELTZ ML: The neurohormone melatonin inhibits cytokine, mitogen and ionizing radiation induced NF-кB. Biochem Mol Biol Int 37: 1063-1070, 1995.

NAGASE M, FUJITA T: Mineralocorticoid receptor activation in obesity hypertension. Hypertens Res 32: 649-657, 2010.

PAULIS L, SIMKO F: Blood pressure modulation and cardiovascular protection by melatonin: potential mechanisms behind. Physiol Res 56: 671-684, 2007.

PAULIS L, PECHANOVA O, ZICHA J, BARTA A, GARDLIK R, CELEC P, KUNES J, SIMKO F: Melatonin interactions with blood pressure and vascular function during L-NAME-induced hypertension. J Pineal Res 48 : 102-108, 2010a.

PAULIS L, PECHANOVA O, ZICHA J, LISKOVA S, CELEC P, MULLEROVA M, KOLLAR J, BEHULIAK M, KUNES J, ADAMCOVA M, SIMKO F: Melatonin improves the restoration of endothelium-derived constricting factor signalling and inner diameter in the rat femoral artery after cessation of L-NAME treatment. J Hypertens 28 (Supp1 1): S19-S24, 2010b.

PECHANOVA O, SIMKO F: Chronic antioxidant therapy fails to ameliorate hypertension: potential mechanisms behind. J Hypertens 27 (Suppl 6): S32-S36, 2009.

PECHANOVA O, BERNATOVA I, PELOUCH V, SIMKO F: Protein remodelling of the heart in NO-deficient hypertension: the effect of captopril. J Mol Cell Cardiol 29: 3365-3374, 1997.

PECHANOVA O, JENDEKOVA L, KOJSOVA S, JAGLA F: Possible role of nitric oxide in the locomotor activity of hypertensive rats. Behav Brain Res 174: 160-166, 2006. 
PECHANOVA O, ZICHA J, PAULIS L, ZENEBE W, DOBESOVA Z, KOJSOVA S, JENDEKOVA L, SLADKOVA M, DOVINOVA I, SIMKO F, KUNES J: The effect of N-acetylcysteine and melatonin in adult spontaneously hypertensive rats with established hypertension. Eur J Pharmacol 561: 129-136, 2007.

PECHANOVA O, PAULIS L, SIMKO F: Peripheral and central effects of melatonin on blood pressure regulation: A review. Int J Mol Sci 15: 17920-17937, 2014.

PECHANOVA O, VARGA Z, CEBOVA M, GIRICZ Z, PACHER P, FERDINANDY P: Cardiac nitric oxide signalling in metabolic syndrome. Br J Pharmacol 172: 1415-1433, 2015.

POZO D, REITER RJ, CALVO JR, GUERRERO JM: Inhibition of cerebellar nitric oxide synthase and cyclic GMP production by melatonin via complex formation with. J Cell Biochem 65: 430-442, 1997.

RAMCHANDRA R, HOOD SG, MAY CN: Central nitric oxide decreases cardiac sympathetic drive and improves baroreflex control of heart failure in ovine heart failure. Am J Physiol Regul Integr Comp Physiol 307: R271R280, 2014.

REITER RJ, CALVO JR, KARBOWNIK M, QI W, TAN DX: Melatonin and its relation to the immune system and inflammation. Ann NY Acad Sci 917: 376-386, 2000.

SHATILO VB, BONDARENKO EV, ANTONIUK-SHCHEGLOVA IA: Metabolic disorders in elderly patients with hypertension and their correction with melatonin. Adv Gerontol 25: 84-89, 2012.

SIEW-KEAH L, SUNDARAM A, SIRAJUDEEN KN, ZAKARIA R, SINGH HJ: Effect of melatonin supplementation and cross-fostering on renal glutathione system and development of hypertension in spontaneously hypertensive rats. J Physiol Biochem 70: 73-79, 2011.

SIMKO F, PECHANOVA O: Potential roles of melatonin and chronotherapy among the new trends in hypertension treatment. J Pineal Res 47: 127-133, 2009.

SIMKO F, PECHANOVA O, PELOUCH V, KRAJCIROVICOVA K, MULLEROVA M, BEDNAROVA K, ADAMCOVA M, PAULIS L: Effect of melatonin, captopril, spironolactone and simvastatin on blood pressure and left ventricular remodelling in spontaneously hypertensive rats. J Hypertens 27 (Suppl 6): S5-S10, 2009.

STRIFFLER JB, BHATHENA SJ, MICAELIS OE IV, CAMPBELL JD, HANSEN CT, SCALBERT E, THIBAULT N, VELASQUEZ MT: Role of angiotensin-converting enzyme inhibition in glucose metabolism and renal injury in diabetes. Metabolism 47: 1199-1204, 1998.

TAN DX, MANCHESTER LC, TERRON MP, FLORES LJ, REITER RJ: One molecule, many derivatives: a neverending interaction of melatonin with reactive oxygen and nitrogen species? J Pineal Res 42: 28-42, 2007.

TOMAS-ZAPICO C, COTO-MONTES A: A proposed mechanism to explain the stimulatory effect of melatonin on antioxidative enzymes. J Pineal Res 39: 99-104, 2005.

VANĚČEK J, JANSKÝ L: Short days induce changes in specific melatonin binding in hamster median eminence and anterior pituitary. Brain Res 477: 387-390, 1989.

XIA CM, SHAO CH, XIN L, WANG YR, DING CN, WANG J, SHEN LL, LI L, CAO YX, ZHU DN: Effects of melatonin on blood pressure in stress-induced hypertension in rats. Clin Exp Pharmacol Physiol 35: 12581264, 2008.

YAMAGUCHI Y, YOSHIKAWA N, KAGOTA S, NAKAMURA K, HAGINAKA J, KUNITOMO M: Elevated circulating levels of markers of oxidative-nitrative stress and inflammation in a genetic rat model of metabolic syndrome. Nitric Oxide 15: 380-386, 2006.

YILDIZ M, SAHIN B, SAHIN A: Acute effects of oral melatonin administration on arterial distensibility, as determined by carotid-femoral pulse wave velocity, in healthy young men. Exp Clin Cardiol 11: 311-313, 2006.

ZHOU YB, SUN HJ, CHEN D, LIU TY, HAN Y, WANG JJ, TANG CS, KANG YM, ZHU GQ: Intermedin in paraventricular nucleus attenuates sympathetic activity and blood pressure via nitric oxide in hypertensive rats. Hypertension 63: 330-337, 2014.

ZHU J, SONG W, LI L, FAN X: Endothelial nitric oxide synthase: a potential therapeutic target for cerebrovascular diseases. Mol Brain 9: 30, 2016. 